\title{
METHODOLOGICAL FEATURES FOR RESTRAINING THREATS TO ORGANIZATIONS
}

\section{Maya Lambovska}

University of National and World Economy, Faculty of Management and Administration, Sofia, Bulgaria

\section{Ognyan Simeonov}

University of National and World Economy, Faculty of Finance and Accountancy, Sofia, Bulgaria

\section{CMESTE}

JEL Category: M10, C65

\begin{abstract}
Methodological features of an original model for restraining threats to organizations are presented in this paper. It is worked out in three sections. Conceptual fundamentals of the model for restricting threats are clarified in the first section. Instruments of the model for restricting threats are presented in the second section. These are focus groups, an open investigation by questionnaires, confidence intervals with four evaluations, fuzzy trapezoidal numbers, fuzzy expertons, fuzzy random incidence matrices and aggregate licensing board of threats to the organization. Stages and procedures of the model for restricting threats are explained in the third section of the paper.
\end{abstract}

Keywords: Strategic management, Restriction on threats, Licensing board of threats, Fuzzy subsets

\section{INTRODUCTION}

The matter of restricting threats to organizations is one of the still undeveloped problems in the scientific literature on management. In this connection, the paper is aimed at presenting methodological features of a model for solving that problem. According to the authors of the paper, methodological features are referred to theories and tools for the model implementation as well as to the stages and procedures of the model. The

The address of the corresponding author:

Maya Lambovska

麦=; mlambovska@abv.bg model for restraining threats is elaborated within the framework of scientific research project "Theoretical fundamentals of an internal standard of measuring and evaluating threats to organizations", financed by the National Science Fund to the Bulgarian Ministry of Education and Science.

The model suggested here consists of evaluating the expected effect on threats to the organization of a package of managerial decisions on restringing these threats. Conceptually, the approach refers to the second step of an internal standard of the organization for measurement, evaluation, and restriction on threats to it. 
This paper is worked out in three sections. Conceptual fundamentals of an original model for restricting threats are clarified in the first section. Instruments of the model for restricting threats are presented in the second section. Stages and procedures of the model are explained in the third section.

\section{CONCEPTUAL BASIS OF THE MODEL FOR RESTRICTING THREATS}

The internal standard for measurement, evaluation, and restriction on threats to organizations is suggested by $\mathrm{O}$. Simeonov. According to him, this standard should be implemented in two steps (Simeonov \& Lambovska, 2010, p. 40).

The first step refers to the application of techniques for identification, measurement, and evaluation of threats. Their elaboration is based on the following activities (Simeonov \& Lambovska, 2010, pp. 40-42):

- Identification of the subjects of threats Parties concerned with the organization, whose actions and/or omissions to act could lead to the threat, are defined as subjects of threat. In this study, they are considered in their capacity of licensing institutions (LIs). They interact with the organization under specific operation parameters of the organization called license parameters (LPs) (Neely, 1998, pp. 121-123).

- Localizing the sources of threats - Deviations of the LPs meanings from the critical borders, determined in the agreements (licenses) with LIs, are defined as sources of threat. Deviations cause negative reactions by the LIs and ultimately termination of interaction with the organization.

- Measuring threats - Two functions are consecutively used for measuring threats. The function of aggression is the first function. It shows the dependence between different values of a license parameter (LP) and degree of aggressiveness of the licensing institution (LI), arising from its negative reaction. The function of threat is the second function. It shows the dependence between the degree of aggressiveness of a $\mathrm{LI}$ and the threat to the organization. This instrumentation is used for presenting a current degree of threat to the organization. Such functions and evaluations are prepared for all LPs included in the licenses of the organization with its LIs.

- Evaluating threats - Threats for all LPs of the organization, arising from its LIs, make it possible to construct licensing board of threats. It was substantiated for the first time by $\mathrm{O}$. Simeonov as an instrument for focusing organizations on their threats (Simeonov, 2004, pp. 102-105). The licensing board is presented in the form of the polygon formed from a "radar" coordinate system by different LIs or for the organization as a whole. In both cases, the size of the threat is measured by the area of the polygon (see Fig. 1), limited by values of threats regarding LPs (Simeonov \& Lambovska, 2010, pp. 41-42).

The second step of the internal standard is associated with a restriction on threats. The elaboration of techniques for implementation of that step is based on the following activities (Simeonov \& Lambovska, 2010, pp. 43-45):

- Development of alternative options for restricting threats - As a result of the first step the organization has already obtained the evaluations of the threats by LPs. Based on these results, managerial decisions (Anguelov \& Stoyanov, 2013, p. 26) are developed which are expected to lead to distancing the LPS values from the critical ones. Greater attention is paid to decisions on the LPs with highest evaluations of threats.

- Evaluation of alternative decisions and selection of a decision package for threats restricting - The evaluation of decisions requires consideration of combined effects of decisions on expected results for threats reducing, mutual effects between decisions by LPs, mutual effects between threats by LPs. Delayed effects of decisions on threats should also be studied. Thus, it comes to the evaluation of packages of decisions and selection of a decision package.

Forecasts are made for each decision package about expected effects of decisions on the meanings of the LPs included in the organization's licensing board of threats. Further on, based on the instrumentation for measuring threats - scales and functions of aggression and of threats, expected effects of decision packages on threats 
to the organization are defined. On this basis is formed a new, expected licensing board of threats to the organization which measures the expected effect of the corrective measures (packages of managerial decisions). The effect of any decision package on restricting threats is evaluated by comparing the current and expected licensing boards of threats to the organization.

The difference between areas of the current and expected licensing boards for each package is the criterion for selection of a decision package (Asenov, 2015, p. 22). The aim is a maximum reduction of the area of the polygon (Zivanovic, Zivanovic, \& Todorova, 2010), limited by expected values of threats. The best package of managerial decisions is the one that minimizes the area of threats to the greatest extent in quantitative terms.

\section{INSTRUMENTS FOR RESTRICTING THREATS}

Instruments for restricting threats, suggested by the authors, are the following:

- Focus groups (FGs);

- Open investigation by questionnaires;

- Confidence intervals with four evaluations from the theory of intervals;

- Mathematical calculations with fuzzy trapezoidal numbers (FTNs), fuzzy expertons, random fuzzy incidence matrices from the fuzzy subset theory; and

- Licensing board from the theory of measurement.

The focus group method (Beshelev \& Gurvits, 1980 ) is used for generating expert evaluations (judgments) in the procedure of forecasting effects of decision packages on threats to the organization. The focus group method is applied in this study due to the absence of sufficient and/or adequately structured retrospective information about evaluated/ forecasted parameters (Beshelev \& Gurvits, 1980, p. 8-9) and mainly due to the authors' belief in the lower utility of statistical methods in forecasting under uncertainty. As a tool for group expert judgments, FGs increase the expertise accuracy by reducing the scale of the error (Beshelev \& Gurvits, 1980, p. 8-9). A group subject called "Decision-making subject (DMS)", used in this model is also considered as a focus group. Its tasks are to evaluate threats to the organization and to make decisions on their restriction. DMS sets up the decision packages on restricting threats. In addition, DMS members generate expert evaluations about the significance of threats arising from the aggressive actions of LIs and forecast the effect of decision packages on the LPs values for the highest threats to the organization.

The evaluation of DMS is performed by open investigation method by questionnaires (Shmerling, Dubrovskiy, Arzhanova, \& Frenkel', 1977 , pp. 298, 301-302). This method is applied to all the DMS activities: setting up decision packages for restricting threats, evaluating the significance of threats by LIs, forecasting decisions effects on threats (including mutual effects between decisions and between threats) to the organization.

Theory of intervals is part of mathematics whose main application is for conditions of subjectivity and uncertainty (Kaufmann \& Gil-Aluja, 1990, p. 21). In this model evaluations/ forecasts are described by intervals which are not characterized by the possibility of occurring (degree of belonging) and convexity (Kaufmann \& Gil-Aluja, 1990, p. 51). The mathematical operations with confidential intervals are used in the model predominantly in the context of expected and therefore uncertain nature of most parameters. It is speaking of a use of confidential intervals with four evaluations, called "confidential fours" as building elements of random fuzzy incidence matrices and of expertons.

In addition to typical mathematical operations between confidential intervals, such as addition, subtraction, multiplication, and division, the socalled "representative number of confidential four" is calculated. It reflects the relative linear distance of an interval to the number "zero" (Kaufmann \& Gil-Aluja, 1987, p. 202) and is calculated using all four characteristic evaluations of the confidential interval. The formula coincides with the Humming's representative number of fuzzy trapezoidal number (FTN) on the explicit condition of absent possibility of occurring (Kaufmann \& GilAluja, 1988, p. 74). The main application of representative numbers is an instrument of defuzzification which refers to a representation of fuzzy numbers and confidential intervals in a discrete form (Bojadziev \& Bojadziev, 1997, pp. 144-148). This application is used in the model to 
define delayed effects between decisions and threats as well as to a clearer presentation of the expected effect of decision packages on threats to the organization.

Theory of fuzzy subsets is part of mathematics which is defined as an improvement of the interval theory (Kaufmann \& Gil-Aluja, 1986, p. 37). When the confidential domain is convex in the mathematical sense, the confidential interval is transformed into a fuzzy subset (Kaufmann \& GilAluja, 1990, p. 54). Or fuzzy subset is described by confidential intervals for any possibility of occurring by the interval $[0,1]$ (Kaufmann \& GilAluja, 1986, p. 37). A stricter mathematical formulation defines the fuzzy subset as a subset of the universal finite set where belonging of the elements to the subset is described by the socalled "characteristic function" or "belonging function", taking values in the interval $[0,1]$ (Zadeh, 1965, p. 345). The instruments of fuzzy subsets theory used in this model are FTNs, fuzzy expertons, and random fuzzy incidence matrices.

FTNs are used for describing DMS members' evaluations/ forecasts about effects of managerial decisions on LIs (respective threats to the organization), mutual effects between decisions and mutual effects between threats. The FTN is a fuzzy number with a linear and continuous characteristic function, which has two evaluations of the possibility of occurring "unity" and two evaluations of the possibility of occurring "zero" (Bojadziev \& Bojadziev, 1997, pp. 24-25). The key problem of FTNs using in this model is associated with the possibility that results from the substitution of the fuzzy forecasts for the LIs/ aggression in the definite (mathematically) aggression/ threat functions could be outside the admissible interval for the functions $[0,1]$ and could even take negative values. The problem is due to the peculiarities of the mathematical operations with fuzzy numbers "pseudocomplementariness", "pseudo-inversion" (Kaufmann \& Gil-Aluja, 1990, p. 35) and the fact that results from the operations "multiplication", "division", and "subtraction" between fuzzy numbers in most cases aren't fuzzy numbers (Kaufmann \& Gil-Aluja, 1987, p. 67). To solve the problem, authors of the paper apply normalization of the expected aggression/ threat in the extreme definite interval of the change of aggression/ threat. Normalization is performed according to a complex formula specially designed for the purpose of the model.

Fuzzy expertons are used in the model for aggregating the evaluations of DMS members. The experton is a function that generalizes fuzzy random incidence matrices whose elements are described by confidence intervals (Kaufmann \& Gil-Aluja, 1988, p. 42). Mathematical operation with fuzzy expertons, used in this model, is the function "maxmin". This function aggregates three types of effects - effects of managerial decisions on threats, mutual effects "decision - decision" and mutual effects "threat - threat", in combined effects of I and II generations of decisions on threats.

Mathematical calculations with random fuzzy incidence matrices are used for aggregation of DMS members' evaluations of effects as well as for evaluation of combined and delayed effects of managerial decisions on threats. Random character of the matrices pertains to the fact that laws on probability distributions of random numbers are described by them. The fuzziness of the matrices is in the context of an FTNs application for presentation of DMS members' evaluations/ forecasts of effects and of confidential fours in the analysis of delayed and combined effects. This model uses three operations with random fuzzy matrices - "maxmin" function, calculation of mathematical expectation of matrices and difference between matrices. The "maxmin" function is applied for evaluating combined effects of I and II generations of decisions on threats. The mathematical expectation aggregates the evaluations of effects by weighing them against the possibilities of their occurring. This calculation is used as a basis for defining delayed effects of decisions on threats. Delayed effects calculation is realized as a difference between representative matrices of mathematical expectations for combined effects of I and II generations and for effects of decisions on threats.

The licensing board is used in the model as a managerial tool for measuring and evaluating expected threats to the organization (Simeonov \& Lambovska, 2010, pp. 41-45). Especially, its present function is to represent the expected effect of the package of managerial decisions on threats to the organization (see Fig. 1). 


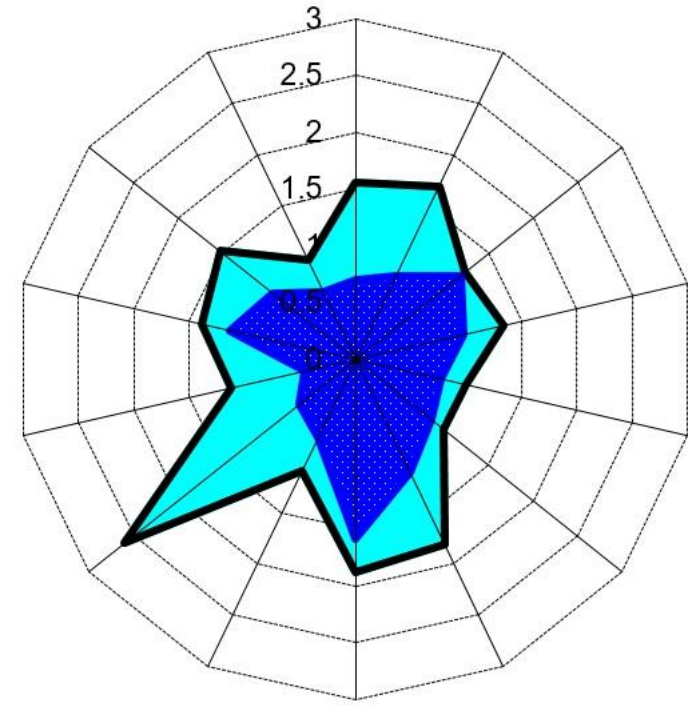

Aggregate licensing board of current threats to the organization

Difference between areas of the polygon of current threats and expected threats to the organization

Aggregate licensing board of expected threats to the organization

Fig. 1 Aggregate licensing board of threats to the organization

\section{STAGES OF THE MODEL FOR RESTRICTING THREATS}

The authors' model for restricting threats to the organization covers four stages:

- Stage I "Defining expected threats to the organization";

- Stage II "Aggregating expected evaluations of (mutual) effects between managerial decisions and threats to the organization";

- Stage III "Evaluation of combined effects of I and II generations and of delayed effects between managerial decisions and threats";

- Stage IV "Evaluation of the expected effect of managerial decisions on threats to the organization".

In stage one of the model, the normalized evaluations of expected threats to the organization are defined. These threats are expected to be achieved because of the application of a package of managerial decisions on restricting threats. Stage one includes four procedures:

- Generation of managerial decisions on restricting threats to the organization;
- Evaluation of expected (mutual) effects between managerial decisions, LPs, and threats to the organization;

- Evaluation of expected threats according to LIs and LPs; and

- Aggregating expected threats according to LPs and DMS members of the organization.

In the first procedure of stage one, a package of managerial decisions on restricting threats to the organization is created. The procedure is performed in two activities: defining the highest current threats to the organization and formation of a package of managerial decisions on restricting threats to the organization. By "the highest threats to the organization" in the model are meant the aggregated current evaluations of threat according to LPs, which are equal to or higher than a specific evaluation. The latter and the decision package are offered by DMS members of the organization.

The purpose of the second procedure of stage one is to generate matrices of (mutual) effect between managerial decisions, LPs, and threats. The procedure is performed in three activities: generation of matrices of managerial decisions effect on LPs, generation of matrices of mutual effect between managerial decisions and generation of matrices of mutual effect between threats to the organization. The evaluations in this procedure refer to decisions and LPs according to the highest current threats to the organization as well as to these threats themselves. They are generated by DMS members. In mathematical terms, the evaluations are represented by FTNs and are systematized into random fuzzy incidence matrices.

The purpose of the third procedure of stage one is to define expected normalized threats to the organization according to LIs and LPS. The procedure is performed in two activities: defining the expected aggression of LIs according to LPs and defining expected threats to the organization according to LIs and LPs. The expected aggression is defined by 1) substituting the DMS members' evaluations of expected effects of managerial decisions on LPs for the highest threats in the functions of aggression of LIs, and 2) subsequent normalization of the obtained fuzzy results in a normalization interval close to the interval $[0,1]$. The first activity is performed in 
compliance with the rules for operations with FTNs. Normalization of the expected aggression involves representing (recalculating) the extreme fuzzy trapezoidal evaluations of aggression in the extreme defined interval of aggression change, formed by substituting the extremely defined evaluations " 0 " and " 1 " for LPs in the defined function of aggression. Expected threats to the organization are defined in analogy with the expected aggression by calculation of the expected threats to the organization from LIs according to LPs and subsequent normalization of the obtained fuzzy results in a normalization interval close to the interval $[0,1]$. The first activity is performed by substituting the normalized aggression of LIs in the functions of threat.

The purpose of the fourth procedure of stage one is to aggregate expected threats by LPs and by DMS members and to perform subsequent normalization in the interval $[0,1]$. The procedure includes three activities: weighing expected threats against the LIs' significance evaluations, aggregation of the weighted expected threats for all LIs and normalization of aggregated expected threats. Normalization of aggregated expected threats involves weighing, against a rounded to an integer bigger number, the maximum aggregated current threat (defined from among the aggregated current threats according to LPs), which is taken as the maximum normalization value - "unity".

Expected evaluations of (mutual) effects between managerial decisions and threats to the organization are aggregated in stage two of the model. This is achieved by forming expertons of effects of the managerial decisions on threats, mutual effects between decisions and mutual effects between threats. Expertons require use of FTNs from the previous stage of the model as confidential intervals with four evaluations. Stage two includes three procedures:

- Calculation of the experton of mutual effects between managerial decisions on restricting threats to the organization;

- Calculation of the experton of mutual effects between threats to the organization; and

- Calculation of the experton of managerial decisions effect on the threats to the organization.
The purpose of the first procedure of stage two is to aggregate mutual effects between managerial decisions on restricting threats through an experton. The procedure includes accumulation of the expected DMS members' evaluations of mutual effects between managerial decisions on restricting threats and formation of the experton of the mutual effects of decisions. The random fuzzy incidence matrix, describing the probability distribution law of the DMS members' evaluations regarding mutual effects between decisions, is formed in the first activity. The experton of mutual effects between managerial decisions is formed in the second activity. It describes the law on the cumulative complementary probability distribution of the evaluations of mutual effects between decisions.

The purpose of the second procedure of stage two is to aggregate mutual effects between threats to the organization through an experton. The procedure is performed in analogy with the previous procedure of the model.

The purpose of the third procedure of stage two is to aggregate effects of managerial decisions on threats to the organization through an experton. The procedure is realized for the normalized aggregated expected effects of decisions on threats in analogy with the previous two procedures.

Combined effects of I and II generations and delayed effects between managerial decisions and threats are evaluated in stage three of the model. This stage includes two procedures:

- Determination of combined effects of I and II generations between managerial decisions and threats to the organization;

- Determination of delayed effects of managerial decisions on threats to the organization.

The purpose of the first procedure of stage three is to combine mutual effects between managerial decisions, mutual effects between threats and effects of managerial decisions on threats in the so-called "combined effects of I and II generations". Combined effects are evaluated by applying the "maxmin" function to the expertons "decision - decision", "threat - threat" and "decisions - threats" from stage two of the model. 
The purpose of the second procedure of stage three is to evaluate delayed effects of managerial decisions on threats to the organization. The procedure includes de-accumulation of the random fuzzy incidence matrices of managerial decisions effects on threats, calculation of the mathematical expectation for the fuzzy matrices of de-accumulated effects of managerial decisions on threats and evaluation of delayed effects of managerial decisions on threats to the organization. The first activity refers to the experton of expected effects of decisions on threats and of the fuzzy matrix of combined expected effects of I and II generations of managerial decisions on threats. The second activity is realized for assessing possibilities of occurring of de-accumulated expected evaluations of managerial decisions effects on threats. Thus, the so-called "representative matrices of mathematical expectations" are generated. Delayed effects are defined by formation of differences between elements of the representative matrices of mathematical expectations for decisions effects on threats and for combined effects of I and II generations of these decisions; and subsequent definition as delayed effects of these differences which are equal to or higher than a given constant, belonging to the interval $(0,1]$.

In stage four of the model, the expected effect of the managerial decisions package on threats to the organization is evaluated. This is realized by three activities: plotting an aggregate licensing board of expected threats to the organization, defining the polygon area of expected threats and calculating the expected effect of the package of managerial decisions on threats to the organization. The difference between the polygon areas of current threats and expected threats to the organization is calculated in the third activity (see figure 1).

\section{CONCLUSIONS}

Three main results are achieved in this paper.

Firstly, a new complex toolkit for the application of an original model for restricting threats to organizations is proposed in this paper. The toolkit of restricting threats combines a variety of qualitative and quantitative methods and instruments from management and mathematical sciences.

Secondly, main features of the authors' model for restricting threats to organizations are systematized in the paper.

Thirdly, the application of various instruments in the stages of the model for restricting threats to organizations is clarified.

According to its authors, the contribution of this paper refers to the original decision proposed here regarding methodological issues related to the application of a model for restricting threats to organizations. In this sense, it can be argued that the paper fills a gap in management science as regards methodological aspects of control on threats to organizations.

\section{WORKS CITED}

Anguelov, K., \& Stoyanov, I. (2013). Aspects of managerial decision making in organizational environments. KSI Transactions on Knowledge Society, 6(2), 25-28.

Asenov, E. (2015). Characteristics of Compliance Risk in Banking. Economic Alternatives (4), 20-28.

Beshelev, S., \& Gurvits, F. (1980). Matematiko-statisticheskiye metody ekspertnykh otsenok. Moskva: Statistika.

Bojadziev, G., \& Bojadziev, M. (1997). Fuzzy logic for business, finance, and management. Singapore: World Scientific publishing.

Kaufmann, A., \& Gil-Aluja, J. (1986). Introduccion de la teoria de los subconjuntos borrosos a la gestion de la empresas. Santiago de Compostela, España: Milladoiro.

Kaufmann, A., \& Gil-Aluja, J. (1987). Tecnicas Operativas de Gestion para el Tratimiento de la incertidumbre. Barcelona, España: Limpergraf S.A. 
Kaufmann, A., \& Gil-Aluja, J. (1988). Modelos para la investigacion de efectos olvidados. Vigo, España: Pugalsa S. A.

Kaufmann, A., \& Gil-Aluja, J. (1990). Laz matematicas del azar y de la incertidumbre. Madrid: Editorial Centro de Estudios Ramon Areces, "Ediciones Graficas Ortega".

Neely, A. (1998). Measuring business performance (1-st ed.). London, England.

Shmerling, D., Dubrovskiy, S., Arzhanova, T., \& Frenkel', A. (1977). Ekspertnyye otsenki. Metody i primeneniye (Obzor). Statisticheskiye metody analiza ekspertnykh otsenok, 290-382.

Simeonov, O. (2004). A Licensing Board - an Instrument for Measuring of the Threats to the Organizations. Crisis Management (2), 102-105.

Simeonov, O., \& Lambovska, M. (2010). Control over threats. Zilina, Slovak Republic: Georg.

Zadeh, L. (1965). Fuzzy sets. Information control (8), 338-353.

Zivanovic, N., Zivanovic, V., \& Todorova, D. (2010). Reengineering of business processes - strategy of turning points in crisis management. Mehanika, transport, komunikacii (2). Retrieved from http://www.mtc-aj.com/academic-journal.php?body=doc2\&doc=474_EN\#.V3feXNR96t8

Received for publication: 04.01.2017

Revision received: $\quad 21.01 .2017$

Accepted for publication: 28.01.2017

\section{How to cite this article?}

Style - APA Sixth Edition:

Lambovska, M., \& Simeonov, O. (2017, July 15). Methodological features for restraining threats to organizations. (Z. Čekerevac, Ed.) MEST Journal, 5(2), 87-94. doi:10.12709/mest.05.05.02.09

Style - Chicago Sixteenth Edition:

Lambovska, Maya, and Ognyan Simeonov. "Methodological features for restraining threats to organizations." Edited by Zoran Čekerevac. MEST Journal (MESTE) 5, no. 2 (July 2017): 8794.

Style - GOST Name Sort:

Lambovska Maya and Simeonov Ognyan Methodological features for restraining threats to organizations [Journal] // MEST Journal / ed. Čekerevac Zoran. - Toronto - Belgrade : MESTE, July 15, 2017. - 2 : Vol. 5. - pp. 87-94.

Style - Harvard Anglia:

Lambovska, M. \& Simeonov, O., 2017. Methodological features for restraining threats to organizations. MEST Journal, 15 July, 5(2), pp. 87-94.

Style - ISO 690 Numerical Reference:

Methodological features for restraining threats to organizations. Lambovska, Maya and Simeonov, Ognyan. [ed.] Zoran Čekerevac. 2, Toronto - Belgrade : MESTE, July 15, 2017, MEST Journal, Vol. 5, pp. 87-94. 